\title{
Experts' opinion about the pediatric secondary headaches diagnostic criteria of the ICHD-3 beta
}

\author{
Aynur Özge ${ }^{1}$, Ishaq Abu-Arafeh², Amy A. Gelfand ${ }^{3}$, Peter James Goadsby ${ }^{4}$, Jean Christophe Cuvellier ${ }^{5}$, \\ Massimiliano Valeriani ${ }^{6,7}$, Alexey Sergeev ${ }^{8}$, Karen Barlow ${ }^{9}$, Derya Uludüz ${ }^{10}$, Osman Özgür Yalın ${ }^{11}$, Noemi Faedda ${ }^{12}$, \\ Richard B. Lipton ${ }^{13}$, Alan Rapoport ${ }^{14}$ and Vincenzo Guidetti ${ }^{15^{*}}$
}

\begin{abstract}
Background: The 2013 International Classification of Headache Disorders-3 was published in a beta version to allow clinicians to confirm the validity of the criteria or suggest improvements based on field studies. The aim of this work was to review the Secondary Headache Disorders and Cranial Neuralgias and Other Headache Disorders sections of ICHD-3 beta data on children and adolescents (age 0-18 years) and to suggest changes, additions, and amendments.

Methods: Several experts in childhood headache across the world applied different aspects of ICHD-3 beta in their normal clinical practice. Based on their personal experience and the available literature on pediatric headache, they made observations and proposed suggestions for the mentioned headache disorders on children and adolescents.

Results: Some headache disorders in children have specific features, which are different from adults that should be acknowledged and considered. Some features in children were found to be age-dependent: clinical characteristics, risks factors and etiologies have a strong bio psychosocial basis in children and adolescents making primary headache disorders in children distinct from those in adults.

Conclusions: Several recommendations are presented in order to make ICHD-3 more appropriate for use in children.

Keywords: Headache, Classification, Childhood headache, Adolescent headache, Primary headache disorders, Migraine, Tension-type headache, Cluster headache
\end{abstract}

\section{Background}

Headache is a frequent cause of pain and significant disability in children and adolescents. Its varying presentations, etiologies, triggers and methods of management can pose diagnostic and therapeutic dilemmas. Secondary headache disorders in childhood are different from the manifestations in adults, and the cause for this difference is unknown. It could be the result of the differences in degree of brain maturation comprising myelination, new synapse formation and synaptic reorganization [1-3]. There is little data about the critics of secondary headache

\footnotetext{
* Correspondence: vincenzo.guidetti@uniroma1.it

${ }^{15}$ Department of Pediatrics and Child and Adolescent Neuropsychiatry,

Sapienza University, Rome, Italy

Full list of author information is available at the end of the article
}

disorders in children and adolescents in the basis of causes and cerebral maturation.

Owing to the high prevalence of childhood headache and the absence of specific objective diagnostic criteria for children, accurate clinical diagnostic criteria are needed.

\section{Methods}

The researchers of this article consist of authors who have written at least 3 prestigious published papers about headache in children and adolescents, and are also members of the International Headache Society Pediatric Special Interest Group. Subgroups of ICHD-3 beta have been distributed among the researchers provided that each individual have at least one published article related to their assigned subgroup. Some members of this Consensus were assigned 
to design and review the fields of the research. All researchers analyzed the ICHD-3 beta criteria and commented on it based on the literature, providing supporting articles. The primary source of literature was Pubmed, and the paper also benefited from other widely used search engines, such as Google Scholar, and reference lists from single articles, reviews and editorials. The draft was later presented to all of the researchers for them to include their personal clinical practices and suggestions on modifying the ICHD-3 beta criteria for all clinical practitioners to be able to better diagnosis. The final draft of the Consensus article has been submitted after multiple revisions.

\section{Headache attributed to trauma or injury to the head and/or neck \\ Comments}

The main presenting symptoms of mild traumatic head injury are headache, fatigue, and dizziness, and difficulty/slow thinking. Sleep disturbances, frustration, forgetfulness, and fatigue were most likely to first develop during follow-up. Irritability and sleep disturbances last longest (16 days), followed by frustration and poor concentration (14 days); nausea, depression, dizziness, and double vision tended to abate quickly. It is known that at 1 month after injury, nearly $25 \%$ of children still had headache, $20 \%$ still complained of fatigue, and nearly $20 \%$ were still having difficulty thinking [4-8]. These symptoms are not different from posttraumatic symptoms reported in adult patients [9].

\section{Recommendations}

These adult diagnostic criteria are very broad and should be emphasized in depth in children and adolescent. These criteria only help defining the relation to the trauma with its subtypes and the grading of its severity (moderate to severe or mild), however the criteria do not help showing accompanied clinical fenotypes for adolescent and pediatric patients. A modified Glasgow coma scale should be used for young children in which scoring should be different for children in order to better reflect developmental characteristics [10].

\section{Headache attributed to cranial or cervical vascular disorder \\ Comments}

All causes of vascular headache can be seen in childhood age with some phenotypic changes. The manifestations of the syndrome of cerebral autosomaldominant arteriopathy with subcortical infarcts and leukoencephalopathy (CADASIL) begin in childhood up to adulthood (8-60 years) patients with headache, or with a family history of early stroke or dementia or mood changes [11-15]. Since few pediatric patients have been reported those with presenting symptoms of headache had migraine with or without aura or atypical migraine. In a large study consisting of 204 pediatric patients with Moyamoya disease suffered headaches with following characteristics: nausea, vomiting, and abdominal pain. Headache could be localized or unlocalized (one parietal, and two temporal). In four patients, headache developed during hyperventilatory conditions such as exercise, crying, or taking hot food. In three of them, a TIA and headache occurred simultaneously on hyperventilation [16]. In patients younger than 18 years, the clinical manifestations of neuro-Behçet's disease are caused mainly by cerebral sinus venous thrombosis or idiopathic intracranial hypertension and symptoms are related to this entity or due to the location of the parenchymal brain involvement $[17,18]$.

Intracranial hemorrhage and arterial ischemic stroke prevalence is $74 \%$ and $21 \%$ in pediatric population. However, there are no specific remarks have been described in headache disorders related to stroke-like episodes in pediatric population [19]. Trauma related cervical or carotid artery dissections are not uncommon during childhood and adolescents. Carotid or vertebral dissection is generally associated with constant unilateral pain (ipsilateral to the dissection), although throbbing, thunderclap, and gradually worsening headaches have been reported as well [20]. Warning signs of headache due to cranial or vascular disorder are as follows; first or worst headache, especially if sudden in onset; headache after effort; onset before 10 years of age; worsening during the observation period; accompanied by vomiting; presence of focal signs and papilledema; and positive family history of stroke or dementia [21].

Headache prevalence in pediatric patients with arteriovenous fistula (DAVF) is very uncommon ( 1 of 58 described cases) with a very young age at men presentation less than 5 years. The limited verbal expression in this age is limited and tinnitus can't be described and we suggest changing the criteria (see Headache attributed to Dural Arteriovenous fistula) [21]. Nine cases have been reported in pediatric patients with a sparse data referring headache characteristics except thunderclap headache [22].

\section{Recommendations}

\section{Headache attributed to Dural Arteriovenous fistula}

3. at least one of the following:

1. headache is accompanied by tinnitus (Children beavior is more important than words, such as covering their ears)

a) headache is accompanied by ophthalmoplegia

b) headache is both progressive and worse in the morning and/or during coughing and/or bending over 


\section{Headache attributed to genetic vasculopathy}

We suggest the criteria to be changed as follows:

1. Migraine like headache attacks

2. Presentation as stroke-like episodes

3. Deterioration in cognitive skills or behavior changes

\section{Headache attributed to non-vascualar intracranial disorder \\ Headache attributed to idiopathic intracranial hypertension (IIH)}

The course of pediatric IIH varies, and a child may vary with present hours to several years after symptoms begin. While headache, nausea, and vomiting are known classic but nonspecific symptoms, patients may complain of blurred vision, diplopia, and stiff neck as well. At presentation, visual acuity loss is reported in 6\%-20\% of pediatric cases, although visual field loss occurs in up to $91 \%$ of cases with a careful anamnesis. Mentioned diagnostic criteria of IIH are far from diagnostic level of children and adolescents [23].

\section{Recommendations}

Proposed criteria for pediatric IIH diagnosis are:

(1) Prepubertal presentation.

(2)If symptoms or signs present, they may only reflect those of generalized intracranial hypertension of papilledema with normal mental status.

(3) Documented elevated intracranial pressure ( $\geq 250 \mathrm{~mm} \mathrm{CSF}$ in adults and $\geq 280 \mathrm{~mm} \mathrm{CSF}$ in children, $250 \mathrm{~mm}$ CSF if the child is not sedated and not obese) in a properly performed lumbar puncture in the lateral decubitus position.

Neonates: $\geq 76 \mathrm{~mm} \mathrm{H}_{2} 0$.

Age $<8$ years with papilledema: $\geq 180 \mathrm{~mm} \mathrm{H}_{2} 0$.

Age $\geq 8$ years or $<8$ years without papilledema: $>250 \mathrm{~mm} \mathrm{H}_{2} \mathrm{O}$.

(4) Normal CSF composition except in neonates who may have up to $32 \mathrm{WBC} / \mathrm{mm} 3$ and protein as high as $150 \mathrm{mg} / \mathrm{dL}$.

(5) No evidence of hydrocephalus, mass, structural, or vascular lesion on MRI, with and without contrast, and MR venography. Narrowing of the transverse sinuses is allowed.

(6)Cranial nerve palsies allowed if they are of no other identifiable etiology and improve with reduction in cerebrospinal fluid pressure or resolution of other signs and symptoms of intracranial hypertension.

(7) No other identified cause of intracranial hypertension. Children should have signs or symptoms consistent with elevated intracranial

pressure not attributed to other causes [23].

\section{Headache attributed to spontaneous intracranial hypotension}

Spontaneous intracranial hypotension $(\mathrm{SIH})$ is a condition in which a patient develops postural headaches because of a leak of the cerebrospinal fluid (CSF) in the dural membrane. The principal presenting symptom of $\mathrm{SIH}$ is headache. The classic definition is orthostatic headache, where severe headache attacks occur when the patient gets to an upright position, which is relieved upon lying flat. Among the features other than headache, posterior neck pain or stiffness, nausea, and vomiting are the most common, being reported by approximately $50 \%$ of patients, and suggest meningeal irritation, particularly when photophobia or phonophobia is also present. Examinations of children can reveal neck stiffness, horizontal diplopia, facial weakness, vestibulocochlear nerve abnormalities (decreased speech discrimination, disturbed diaphosone tests, disturbed posturography etc), radicular features (pain, dermatomal hypoesthesia, radicular weakness, etc), cerebellar ataxia, and encephalopathy. Children show these values approximately 20 to $30 \mathrm{mmH}_{2} \mathrm{O}$ higher than adults. However, lumbar puncture is not recommended for confirmation in all cases because of the possibility of worsening of the patients' symptoms by further reducing CSF volume [23].

\section{Recommendation}

The following diagnostic criteria should be added to the text. "Children show initial pressure values approximately 20 to $30 \mathrm{mmH}_{2} \mathrm{O}$ higher than adults in lumbar puncture procedures."

Syndrome of transient headache and neurological deficits with cerebrospinal fluid Lymphocytosis (HaNDL)

Review of the literature identifies 14 cases of HaNDL in the pediatric population. This syndrome may mimic much more common conditions such as complicated or hemiplegic migraine, aseptic meningitis, meningoencephalitis, or stroke. This clinical syndrome is under recognized and underreported. HaNDL remains a diagnosis of exclusion especially in children and adolescents [24]. We don't have any recommendation for this title.

\section{Headache attributed to intracranial neoplasm Comments}

Brain tumors are rare in children, with an incidence of 5 per 100,000 in the range of from 0 to 19 years of age group. In infants, brain tumors present with fewer dramatic symptoms due to the accommodation of the skull bones when the fontanels and sutures are still open. 
Both the presence of a brain tumor and its management with radiation increase the risk of additional neurovascular events compared to the general pediatric population (548 per 100,000 vs $2-8$ per 100,000 ) [25-27].

\section{Recommendations}

The following changes might be added in the diagnostic criteria for section 3 of ICHD-3 beta (Headache attributed to intracranial neoplasm) [25-27].

3. Headache has at least one of the following characteristics

a. progressive worse in the morning or after daytime napping or awakes child from sleep

b. projectile vomiting

c. alterations in consciousness

d. seizures

e. starts after physical effort or worsens after the Valsalva Maneuver

f. associated with endocrine alterations

g. showing visual disturbance unrelated to the migraine

h. persistent localized pain

\section{Headache attributed to epileptic seizures}

Since these criteria are general and rely on cause and effect we suggest accepting the adult criteria as well [28]. "Hemicrania epileptic" is restrictive diagnosis in children and adolescents [29]. This condition is extremely rare, and when it does appear, it is unlikely to meet all proposed diagnostic criteria. Hemicrania epileptica is not listed among the nosological or terminological recommendations of the ILAE Commission on Classification and Terminology [30]. In an introductory article, Isler et al. studied 91 patients with drug-resistant epilepsy; of the total, 18 presented hemicranial headache with migrainelike characteristics lasting seconds to minutes at the time of onset of epileptic activity, which was partial seizure in all patients. In rare cases, ictal headache lasted for hours but always need EEG corroborative evidence [31].

We need more data about children and adolescents for reaching the best point.

\section{Headache attributed to Chiari malformation type I Comments}

More typically, CM-1 presents in young adults with neurological symptoms including a headache, cervical pain, cranial nerve palsies, neurosensory deficit, and ataxia. Headache is the most common presentation symptom of Chiari malformation commonly provokes by Valsalva maneuver. Most cases describe headaches similar to primary headache disorders like migraine or tension-type headaches. Only $6 \%$ of patients reported of occipital headache attacks [32-34].

\section{Recommendations}

We suggest that "occipital location of headache attacks is not a rule" in children and adolescents.

\section{Headache attributed to substance or withdrawal}

There is almost no specific report has been published regarding the relation between substance abuse and headache disorders in children and adolescents. Illicit drug use may be complicated by reversible cerebral vasoconstriction syndrome manifesting as thunderclap headache [35, 36]. Alcohol induced headache reported to have migraine like headache tension cluster headache and triggers of less frequent types of primary headache such as familial hemiplegic migraine, hemicrania continua, and paroxysmal hemicrania with no specific reports specific reports in children and adolescents [36].

\section{Medication overuse headache}

Overuse of nonspecific analgesics is most common in adults overall and this appears to be the case in children as well. In a small study of forty-two pediatric chronic daily headache patients with medication overuse more than half were overusing non-steroidal antiinflammatory drugs (NSAIDs), about a quarter acetaminophen, and only $12 \%$ were overusing prescription medications. More data are needed to clarify which types of medications children and adolescents are overusing [37, 38].

However, since the generality of these adult criteria (Medication overuse headache) we suggest accepting these criteria up to detailed description in pediatric patients.

\section{Headache attributed to infection}

Headache attributed to intracranial infection

Adult criteria are general and related to cause and effect can be used for pediatric patients.

\section{Headache attributed to bacterial meningitis or meningoencephalitis}

It is known that nearly $24.9 \%$ of the patients exhibited signs of meningeal irritation in children especially under 3 years of age. The prevalence of all other symptoms and signs were less than 20\% [39]. On the other side, bacterial meningitis is present in 30\% of children with signs of meningeal irritation. Presence of meningeal irritation assessed by the pediatrician is related to bacterial meningitis in $39 \%$. The meningoencephalitis seldom affected children absent fever and neck stiffness. The etiology was known in only $22.4 \%$ of the cases, entero viruses being the most frequent causative agent in young children [40].

Criterion-A- 4 should be changed for children as follows:

a) holocranial

b) located in the nuchal area and associated with neck stiffness. 
These symptoms are missing in some cases of pediatric intracranial infection [41]. Some cases of children and infants, immunosuppressed patients present meningoencephalitis absent neck stiffness or any other signs of meningeal irritation.

We suggest to add the following item on the ICHD-3B criteria for the diagnosis of Headache attributed to bacterial meningitis or meningoencephalitis; some cases of meningoencephalitis could be presented without meningeal irritation signs.

\section{ICHD-3B Headache attributed to brain abscess \\ Comments}

Fever and headache are the most common presenting symptoms of brain abscess in children and adolescents. The main predisposing factor is cyanotic congenital heart disease, sinusitis, otitis, or dental infections. Because of this, the location of abscess can often reveal the primary infection site. Presentations of brain abscesses are relatively nonspecific and occur due to focal mass expansion, intracranial hypertension, or diffuse destruction. Headache, fever, altered level of consciousness, nausea, vomiting, and focal neurologic deficits are common symptoms. Importantly, seizures occur in $30-50 \%$ of patients. Children and adolescents with intravenous or nasal substance users have an increased risk for brain abscess in case of patent foramen ovale $[42,43]$.

\section{Comment regard the sections "Headache attributed to} brain abscess, Headache attributed to subdural, empyema, Headache attributed to systemic infection" of ICHD-3B

Since the general description of the symptoms and the relations to abscess, or subdural empyema or systemic bacterial infection systemic viral infection appearance or recovery adult criteria may be used for pediatric patients.

\section{Recommendations}

Children and adolescents with intravenous or nasal substance users have an increased risk for brain abscess in case of patent foramen ovale.

\section{Headache attributed to disorders of homeostasis Comments}

These criteria have a good generalizability, since no specific description for pediatric headaches is given.

\section{Hypoxia and/or Hypercapnia}

\section{High-altitude headache}

\section{Comments}

Pediatric studies on high-altitude headache are very limited, but adult criteria can be applied in younger patients because they are nonspecific and very general
[44]. High-altitude headache may be associated with physiologic changes such as vasogenic edema, pulmonary edema, and hematologic disorders. Therefore, since headache is a nonspecific symptom, especially in young patients, a sentence should be added regarding the exclusion of other factors that may be associated with headache such as ophthalmological disturbances, sleep disturbances, and acute cerebral dysfunction of extreme altitude related to additional acute cerebral hypoxia. Headache is also a common symptom of chronic mountain sickness, manifested by physical and mental tiredness, feeling of sadness, shortness of breath upon awakening, palpitations, muscle and/or joint pains, cyanosis of the lips, face, and hands, venous dilation in hands and feet, paresthesias in the distal extremities, dizziness, and tinnitus. Parents should be alert to these symptoms. In acute mountain syndrome, headache may be the only complaint [45-47].

\section{Recommendations}

Ruling out high-altitude disease is very important, especially in very young individuals in whom verbal communication is poor, as well in all secondary headaches in young patients and as in some adults.

\section{Headache attributed to airplane travel Comments}

In the pediatric age group, headaches caused by air travel in are not necessarily unilateral, and the pain may be of any type. "As with other secondary headache the description of headache by pediatric patient may be not specific" Parents may sometimes infer the headache. If possible, sinus disease should be ruled out. A past history of any type of headache should be considered, because airplane travel may act as a trigger in patients predisposed to headaches $[48,49]$.

\section{Recommendation}

We need more data in children and adolescents to make good recommendations.

\section{Diving headache \\ Comments}

The ICHD-3 beta criteria for diving heading have moderate validity but poor reliability. They are more applicable to adolescents than young children. Children are more prone to be diving complications (dizziness, personality changes, confusion, and headache) than adults, and various diving organizations have prohibited diving in children less than 12-15 years old (depending on the organization) [50].

\section{Recommendations}

1. The criteria for pediatric diving headache should be changed to headache that appears at a depth. 
2. Adult criteria may be applied in adolescents more than 15 years old, when diving complications are similar to those in adults.

3. Diving headache may also be due to severe complications of diving to which children less than 12 years old are highly prone. Therefore, a remark should be added that the diagnosis should be made retrospectively after few days, if no other diving complications appear.

\section{Sleep apnea headache \\ Comments}

The criteria for sleep-apnea-related headache have moderate reliability but poor validity in the pediatric age group $[51,52]$. Criteria B (apnea-hypopnea index $>5$ ) cannot be applied to children and adolescents since different norms of polysomnographic respiratory values are reported for different age groups (infancy, toddlers, adolescents). There are few reports of the characteristics of sleep apnea headache in pediatric patients [52]. As opposed to adults, the most common pathophysiologic factor associated with obstructive sleep apnea in pediatric patients is adenoid hypertrophy in young children and obesity in adolescents [51-53].

\section{Recommendations}

Criteria B should be accepted, with the addition of the following remark/change: Sleep apnea has been diagnosed according to normal age- related polysomnographic respiratory values. The pathophysiologic factors of adenoid hypertrophy in children and obesity in adolescents should be added to the ICHD-3 criteria.

Key point: Usually, if adenoid hypertrophy or obesity is diagnosed as a cause of sleep apnea, the headache is significantly alleviated or eliminated after adenoidectomy, weight loss, or treatment with positive airway pressure.

\section{Dialysis headache \\ Comments}

The precise mechanism of dialysis headache is not fully understood. Laboratory findings in adults include an increase in levels of nitric oxide, CCRP, and urea, low bicarbonate level, electrolyte imbalance, and hypertension. As these may complicate pediatric dialysis as well, the same diagnostic criteria are probably applicable to both adults and children $[54,55]$.

\section{Recommendation}

We need more data in children and adolescents to make good recommendations.

\section{Headache attributed to arterial hypertension Comments}

Hypertension is defined as an average systolic and diastolic blood pressure $20 \mathrm{mmHg}$ above the 95th percentile for age, sex, and height. Pediatric hypertension resembles adult hypertension, although the risk factors differ [56]. The ICHD-3 beta criteria for arterial hypertension-related headache are highly reliable for older children, in whom there is a higher incidence of essential hypertension, but moderately reliable in young children, in whom arterial hypertension is usually secondary to another disease. Children have a high prevalence of chronic renal, vascular, and endocrine background diseases that can cause headache. Concomitant high blood pressure and headache has been reported in the 7-18-year age group; the headache resolves with treatment of the hypertension [57-59].

\section{Recommendations}

1. Changing the $B$ criteria would increase the generalizability for children and adolescents as follows:

$\mathrm{B}$ : Because the definition of childhood hypertension is based on the normative distribution of blood pressure in healthy children, each measurement must be related to blood pressure standards based on age, sex, and height.

2 . In the E criteria, an underlying systemic disease as a cause for both hypertension and headache should be excluded.

3. We suggest that a pediatric nephrologist be consulted to ensure that the patient has real hypertension according to the published definitions. White coat hypertension should be excluded as well.

\section{Headache attributed to pheochromocytoma Comments}

There is sacristy of reports in the literature regarding pediatric headache relating to pheochromacytoma [60-64]. There is no specific description for headache was given but in a case report a thunderclap headache was reported. Since no specific description is given to the headache in adult criteria, these criteria may be implied for pediatric patients.

\section{Headache attributed to hypertensive crisis without hypertensive encephalopathy Comments}

The ICHD-3 beta criteria have high reliability but moderate validity, with overlap between adult and pediatric symptoms. Hypertensive crisis is defined as a sudden and abrupt elevation in blood pressure from baseline. The exact values are not fully established in children $[65,66]$.

\section{Recommendations}

The criterion of pulsating headache, which is difficult to diagnose in children, should be changed as follows: Pulsating-type headache is not a mandatory finding in children with suspected hypertensive crisis; any type of headache is acceptable as a criterion provided the hypertension and headaches are not better accounted for by an underlying disease. 


\section{Headache attributed to hypertensive encephalopathy Comments}

Most studies describe the same symptoms as described in adults criteria, but headache accompanied symptoms that appear in section 3 of the adult criteria are not described in the pediatric literature [65-68].

\section{Recommendations}

We recommend accepting the adult criteria but section 3 of the accompanied symptoms should not be a criteria.

We suggest section to delete as follows;

3. headache has at least two of the following three characteristics:

a) diffuse pain

b) pulsating quality

c) aggravated by physical activity

\section{Headache attributed to pre-eclampsia or eclampsia Comments}

The ICHD-3 beta criteria for pre-eclampsia/eclampsiaassociated headache have high reliability and validity in adolescents since headache symptoms at this age group resemble adult headache. Perpubertal children are not expected physiologically to be pregnant. The symptoms overlap with adult pre-eclampsia or eclampsia. The risk is higher up to age 19 years, so the rate of headache may be higher in that age group as well [69]. Severe vasoconstriction often develops in women with pre-eclampsia, especially when blood pressure is poorly controlled, and can cause brain infarction and hemorrhage. Reversible cerebral vasoconstriction syndrome (RCVS), also referred to as postpartum angiopathy and Call-Fleming syndrome, can develop during the puerperium in the absence of hypertension or other features of preeclampsia. Pre-eclampsia, eclampsia, and RCVS can all be complicated by PRES [70].

\section{Recommendations}

Since headache may be the presenting symptom of other pregnancy- related complications, criteria D should be changed as follows:

D: not better accounted for by another ICHD-3 diagnosis or other pregnancy-related neurologic co-morbidity.

\section{Headache attributed to autonomic dysreflexia}

This type of headache is under recognized in adult patients [71]. Adult criteria based on the that summarized data un adult patients. We had a large report regarding to this type of headache [71]. In the literature no headache was reported in children less than 5 years old [72] and the headache characteristics were not defined in the few cases reported in the adolescents [73].

\section{Recommendation}

We need more data in children and adolescents to make good recommendations.

\section{Headache attributed to hypothyroidism Comments}

The ICHD-3 beta criteria for hypothyroidism-associated headache have high reliability in adolescents owing to the overlap of clinical symptoms in this age group with adults. Reliability is only moderate for younger patients who may have atypical symptoms. The only report regarding hypotyroidism in pediatric patients described migraine feature of hypothroidsm [74, 75].

\section{Recommendation}

We need more cases in children and adolescents to make good recommendations.

\section{Headache attributed to fasting Comments}

The types of headache described in the literatures regarding fasting headache is Tension-type headache, migraine and cluster headache [76-78]. The ICHD-3 beta criteria for fasting-related headache have high reliability for adolescents. There are no data for children in the literature, although our experience shows that fasting is a predisposing factor for headaches in this age group. The validity is also high for adolescents, who are included in the published studies, but poor for young children. We presume that in children symptoms may appear sooner after the start of fasting owing to their lower glycogen storage capacity and higher sensitivity to dehydration. Furthermore, most studies were performed in adults after prolonged fasting/starvation (during Ramadan in Muslims or after Yom Kippur in Jews), without any satifying data on childhood headaches [76-78].

\section{Recommendation}

Headache may appear earlier in the young patients.

\section{Cardiac Cephalalgia Comments}

Cardiac cephalalgia is very rare and data in the literature are limited including children and adolescents [79].

\section{Headache attributed to disorder of homoeostasis Comments}

We need more cases in children and adolescents to make good recommendations. 
Headache or facial pain attributed to disorders of the cranium, neck, eyes, ears, nose, sinuses, teeth, mouth or other facial or cervical structure

This general Criteria is "very general" and can be implied for pediatric population since it connects objective finding of above structure (cranium neck etc) with clinical, laboratory or imaging evidence to the pain that is attributed to the lesion [80].

\section{Headache attributed to temporomandibular disorder (TMD)}

In children and adolescents with headache, it is important to look for signs and symptoms of temporomandibular joint dysfunction, which occurs with relatively high frequency in the pediatric population. Symptoms in children include pain in the pre-auricular area, pain during masticatory movements, headaches, restricted masticatory movements, and presence of joint noises but at a lower frequency than in adults. The risk is higher intense than in calm children. Both temporomandibular joint dysfunction and its associated headaches can occur in early life and become recurrent in adolescence. They are often related to growth and articular remodeling and disappear with time. For example, chewing noises and altered mandibular function can be attributed to changes in the contour of the temporo-mandibular joint with age. However, it is still unknown if these alterations manifest afterwards as pathological symptoms. The headache pain may be constant or throbbing and may mimic tension type headache. It is often triggered by jaw movement or pressure on the masticatory muscles [81-83]. For ICHD-3 our recommendation is as follows;

1. The criterion for restricted mouth opening should be used according to pediatric published criteria [84]

2. The differential diagnosis of headache due to temporo-mandibular joint dysfunction from tensiontype headache should be noted.

3. We recommend to use with the above limitation of adult criteria due to the previous report regarding cause and effect [83-85].

\section{Headache attributed to psychiatric disorder}

There is already a comprehensive statement in ICHD-3 beta: In children and adolescents, primary headache disorders (migraine, episodic tension-type headache and especially chronic tension-type headache) are often comorbid with psychiatric disorder. Sleep disorders, post-traumatic stress disorder, social anxiety disorder (school phobia) attention-deficit/hyperactivity disorder (ADHD), conduct disorder, learning disorder, enuresis, encopresis and tic disorder should be carefully looked for and treated when found, considering their negative burden in disability and prognosis of pediatric headache. This statement is proved by pediatric reports regarding headache and psychiatric disorders [85-90].

For ICHD-3 our recommendation is as follows; children with ADHD, developmental disorders, depressive disorders or anxiety disorders have an increased risk for headache disorders. Some of these cases present clinical pictures of primary headache disorders like migraine or $\mathrm{TTH}$.

\section{Painful cranial neuropathies and other facial pains Classical trigeminal neuralgia (TGN)}

There are very few reports of TGN in the pediatric literature. The symptoms of trigeminal neuralgia in the few $\mathrm{s}$ cases described in the literature are the same as adults. We believe it would be judicious to include paroxysmal extreme pain disorders in and around the eyes, occipital and/or the submaxillary or submandibular regions commonly presented as a neuropathy [91].

\section{Limitations of the paper}

In pediatric medicine, the age of the patient and the education of the parents may affect the reliability and validity of the diagnosis. There may also be differences in diagnostic accuracy by language and culture. This paper is based on the data reported in the literature and the personal experience of pediatric headache specialists. We did not use a common database to calculate the validity, sensitivity, or specificity of the ICHD-3 beta criteria. We are planning to organize a prospective language-adapted study supported by clinical assessments of video-taped interviews. Furthermore, some of our comments were restricted by a sparsity of data or absence of knowledge on the applicability of specific aspects/points to the pediatric population.

\section{Implications of the paper}

This is the first detailed evaluation of the diagnostic criteria of headache by headache experts from all over the world. All authors based their comments and recommendations on their personal experience with support from the data in the literature specifically pertaining to the pediatric population. This paper supports the distinction between pediatric and adult headache. We trust that with the accumulation of data, the next version of the ICHD will include specific subsections with separate definitions/criteria of pediatric headache.

\section{Conclusions}

- Children are not simply small adults. They have distinct biopsychosocial attributes that play a clear role in the pathogenesis and presentation of secondary headache disorders, with important differences from adults. 
- It is important that physicians be alert to the specific characteristics of pediatric secondary headache disorders for effective diagnosis and management.

- The next version of the ICHD should include specific subtopics of pediatric headaches.

\section{Funding}

This study has not a funding.

Availability of data and materials

All data generated or analyzed during this study are included in this article.

\section{Authors' contributions}

AÖ, the owner of the idea for this paper. She put together the study group, composed its design, collected the reports and wrote the original draft after taking into consideration suggestions by entire authors. IAA, as the head of the pediatric special interest group of the IHS, specifically gave key recommendations on the topics of migraine. AAG has helped with and supported the study design and revised the paper. PJG, helped with and supported the study design and revised the paper and the final version. JCC, helped with sections 9, 11 and 13 of the paper. - MV, helped with sections 6 and 7 of the paper. AS, helped with section 7 of the paper. $\mathrm{KB}$, helped with section 5 of the paper. DU, helped with sections 6 and 8 of the paper. OÖY, helped with section 11 of the paper. NF helped with the writing and review process. RBL, helped create and supervise the main idea of the paper. AR, helped with and supported the study design and revised the paper and the final version. VG, is co-owner of the main idea of the paper. He also supervised the creating collaboration and writing of the paper. All authors read and approved the final manuscript.

\section{Ethics approval and consent to participate}

Not applicable

\section{Consent for publication}

Not applicable

\section{Competing interests}

The authors declare that they have no competing interests.

\section{Publisher's Note}

Springer Nature remains neutral with regard to jurisdictional claims in published maps and institutional affiliations.

\footnotetext{
Author details

${ }^{1}$ Department of Neurology, Mersin University Medical Faculty, Mersin, Turkey. ${ }^{2}$ Royal Hospital for Sick Children, Glasgow G3 8SJ, UK. ${ }^{3}$ UCSF Headache Center and UCSF Benioff Children's Hospital Pediatric Brain Center 2330 Post St, 6th Floor, Campus Box 1675, San Francisco, CA 94115, USA. ${ }^{4}$ NIHR-Wellcome Trust King's Clinical Research Facility, King's College London, London, UK. ${ }^{5}$ Division of Paediatric Neurology, Department of Paediatrics, Lille Faculty of Medicine and Children's Hospital, Lille, France. ${ }^{6}$ Division of Neurology, Ospedale Pediatrico Bambino Gesù, Piazza Sant'Onofrio 4, Rome, Italy. ${ }^{7}$ Center for Sensory-Motor Interaction Aalborg University, Aalborg, Denmark. ${ }^{8}$ Department of Neurology and Clinical Neurophysiology, University Headache Clinic, Moscow State Medical University, Moscow, Russia. ${ }^{9}$ Faculty of Medicine, University of Calgary, Alberta Children's Hospital, C4-335, 2888 Shaganappi Trail NW, Calgary, AB T3B 6A8, Canada.

${ }^{10}$ Cerrahpaşa Medical Faculty, Deaprtment of Neurology, İstanbul University, Kocamustafapaşa, İstanbul, Turkey. ${ }^{11}$ Istanbul Research and Education Hospital, Kocamustafapaşa, İstanbul, Turkey. ${ }^{12}$ Phd program in Behavioural Neuroscience, Department of Paediatrics and Child and Adolescent Neuropsychiatry, Sapienza University of Rome, Rome, Italy. ${ }^{13}$ Department of Psychiatry and Behavioral Sciences, Department of Epidemiology \& Population Health, Montefiore Headache Center, Albert Einstein College of Medicine, Bronx, NY, USA. ${ }^{14}$ The David Geffen School of Medicine at UCLA, Los Angeles, CA, USA. ${ }^{15}$ Department of Pediatrics and Child and Adolescent Neuropsychiatry, Sapienza University, Rome, Italy.
}

Received: 5 September 2017 Accepted: 9 November 2017 Published online: 29 November 2017

\section{References}

1. International Classification of Headache Disorders-3 (beta version) (2013) Cephalalgia 33:629-808

2. Albers L, Straube A, Landgraf MN et al (2014) High diagnostic stability of confirmed migraine and confirmed tension-type headache according to the ICHD-3 Beta in adolescents. J Headache Pain 10:15-36

3. Sharma N, Mishra D (2014) International classification of headache disorders: what the pediatrician needs to know! Indian Pediatr 51:123-124

4. Choe MC, Blume HK (2016) Pediatric posttraumatic headache: a review. J Child Neurol 31(1):76-85

5. Kirk C, Nagiub G, Abu-Arafeh I (2008) Chronic post-traumatic headache after head injury in children and adolescents. Dev Med Child Neurol 50:422-425

6. Callaghan M, Abu-Arafeh I (2001) Chronic post-traumatic headache in children and adolescents. Dev Med Child Neurol 43:819-822

7. Abu-Arafeh I, Howells R (2014) Chronic post-traumatic headache in pediatrics. Pain Manag 4:303-308

8. Pinchefsky E, Dubrovsky AS, Friedman D et al (2015) Part I-evaluation of pediatric post-traumatic headaches. Pediatr Neurol 52(3):263-269

9. Bazarian JJ, Wong T, Harris M et al (1999) Epidemiology and predictors of post-concussive syndrome after minor head injury in an emergency population. Brain Inj 13(3):173-189

10. Holmes JF, Palchak MJ, MacFarlane T et al (2005) Performance of the pediatric glasgow coma scale in children with blunt head trauma. Acad Emerg Med 12(9):814-819

11. Desmond DW, Moroney JT, Lynch T et al (1999) The natural history of CADASIL: a pooled analysis of previously published cases. Stroke 30(6): $1230-1233$

12. Harley J, Westmacott R, Decker J et al (2010) Childhood-onset CADASIL: clinical, imaging, and neurocognitive features. J Child Neurol 25(5):623-627

13. Cleves C, Friedman NR, Rothner AD et al (2010) Genetically confirmed CADASIL in a pediatric patient. Pediatrics 126:1603-1607

14. Granild-Jensen J, Jensen UB, Schwartz M et al (2009) Cerebral autosomal dominant arteriopathy with subcortical infarcts and leukoencephalopathy resulting in stroke in an 11-year-old male. Dev Med Child Neurol 51(9):754-757

15. Desmond DW, Moroney JT, Lynch T et al (1999) The natural history of CADASIL: a pooled analysis of previously published cases. Stroke 30: $1230-1233$

16. Seol HJ, Wang KC, Kim SK et al (2005) Headache in pediatric moyamoya disease: review of 204 consecutive cases. J Neurosurg 103(5):439-442

17. Uluduz D, Kürtüncü M, Yapıcı Z et al (2011) Clinical characteristics of pediatric-onset neuro-Behçet disease. Neurology 77:1900-1905

18. Cakar N, Başaran O, Uncu N et al (2014) Clinical characteristics of paediatric neuro-Behçet's disease: a single tertiary centre experience. Clin Exp Rheumatol 32(4):165-170

19. Deng $Y$, Wang $Y$, Yang $W$ et al (2015) Risk factors and imaging characteristics of childhood stroke in china. J Child Neurol 30(3):339-343

20. Stence NV, Fenton LZ, Goldenberg NA et al (2011) Craniocervical arterial dissection in children: diagnosis and treatment. Curr Treat Options Neurol 13:636-648

21. Roser T, Bonfert M, Ebinger F et al (2013) Primary versus secondary headache in children: a frequent diagnostic challenge in clinical routine. Neuropediatrics 44:34-39

22. Walcott BP, Smith ER, Scott RM et al (2013) Dural arteriovenous fistulae in pediatric patients: associated conditions and treatment outcomes. $J$ Neurointerv Surg 5(1):6-9

23. Ozge A, Bolay H (2014) Intracranial hypotension and hypertension in children and adolescents. Curr Pain Headache Rep 18(7):430

24. Filina T, Feja KN, Tolan RW (2013) An adolescent with pseudomigraine, transient headache, neurological deficits, and lymphocytic pleocytosis (HaNDL syndrome): case report and review of the literature. ClinPediatr (Phila) 52:496-502

25. Abend NS, Younkin D, Lewis DW (2010) Secondary headaches in children and adolescents. Semin Pediatr Neurol 7:123-133

26. Molineus A, Boxberger N, Redlich A et al (2013) Time to diagnosis of brain tumors in children: a single-centre experience. Pediatr Int 55(3):305-309

27. Ullrich NJ (2009) Neurologic sequelae of brain tumors in children. J Child Neurol 24(11):1446-1454 
28. Kanemura H, Sano F, Ishii S et al (2013) Characteristics of headache in children with epilepsy. Seizure 22:647-650

29. Lieba-Samal D, Wöber C, Waiß C, Kastiunig T, Seidl M, Mahr N, et al. Field testing of ICHD-3 beta criteria of periictal headaches in patients with focal epilepsy - a prospective diary study. Cephalalgia 0(0):1-6. doi:10.1177/ 0333102416684343. Available at http://journals.sagepub.com/doi/pdf/10. 1177/0333102416684343

30. Scheffer IE, Berkovic S, Capovilla G, Connolly MB, French J et al (2017) ILAE classification of the epilepsies: position paper of the ILAE Commission for Classification and Terminology. Epilepsia 58(4):512-521

31. Isler H, Wieser HG, Egli M (1987) Hemicrania epileptica: synchronous ipsilateral ictal headache with migraine features. In: Andermann F, Lugaresi E (eds) Migraine and epilepsy. Butterworth, Boston, pp 249-263

32. Aitken LA, Lindan CE, Sidney S et al (2009) Chiari type I malformation in a pediatric population. PediatrNeurol 40:449-454

33. Patra KC, Kirtane AP (2016) Not all cases of nyctalopia are benign: unusual and serendipitous presentation of Arnold-Chiari type 1 malformation at a Pediatric tertiary care Center. J Pediatr Neurosci 11(3):244-248

34. Toldo I, Tangari M, Mardari R et al (2014) Headache in children with Chiari I malformation. Headache 54(5):899-908

35. Beckmann YY, Seçkin M, Manavgat Al et al (2012) Headaches related to psychoactive substance use. Clin Neurol Neurosurg 114(7):990-999

36. Panconesi A (2016) Alcohol-induced headaches: evidence for a central mechanism? J Neurosci Rural Pract 7(2):269-275

37. Chiappedi M, Balottin U (2014) Medication over use headache in children and adolescents. Curr Pain Headache Rep 18(4):1-6

38. Gelfand AA, Goadsby PJ (2014) Medication overuse in children and adolescents. Curr Pain Headache Rep 18:1-6

39. Zhang J, Hu X, Hu X, Ye Y, Shang M, An Y et al (2016) Clinical features, outcomes and molecular profiles of drug resistance in Tuberculous meningitis in non-HIV patients. Sci Rep 7(6):19072

40. Vâță A, Luca CM, Duca E, Irina T, Manciuc C, Vâță LG, Dorobăț C (2013) Viral meningitis admitted to an infectious diseases hospital: a retrospective case series. Rev Med Chir Soc Med Nat lasi 117(2):476-482

41. Michos AG, Syriopoulou VP, Hadjichristodoulou C et al (2007) Aseptic meningitis in children: analysis of 506 cases. PLoS One 2:674

42. Ozsürekçi $Y$, Kara A, Cengiz AB et al (2012) Brain abscess in childhood: a 28year experience. Turk J Pediatr 54:144-149

43. Bonfield CM, Sharma J, Dobson S (2015) Pediatric intracranial abscesses. J Inf Secur 71:42-46

44. Lagman-Bartolome AM, Gladstone J (2014) Metabolic headaches. Neurol Clin 32(2):451-469

45. Wilson MH, Newman S, Imray CH (2009) The cerebral effects of ascent to high altitudes. Lancet Neurol 8:175-191

46. Pollard AJ, Niermeyer S, Barry P et al (2001) Children at high altitude: an international consensus statement by an ad hoc committee of the International Society for Mountain Medicine, march 12, 2001. High Alt Med Biol 2:389-403

47. Mainardi F, Lisotto C, Maggioni F et al (2012) Headache attributed to airplane travel ('airplane headache'): clinical profile based on a large case series. Cephalalgia 32:592-599

48. Ipekdal HI, Karadaş O, Erdem G et al (2010) Airplane headache in pediatric age group: report of three cases. J Headache Pain 11:533-534

49. Berilgen MS, Müngen B (2011) A new type of headache, headache associated with airplane travel: preliminary diagnostic criteria and possible mechanisms of aetiopathogenesis. Cephalalgia 31:1266-1273

50. Harmsen S, Schramm D, Karenfort M, Christaras A, Euler M, Mayatepek E et al (2015) Presumed arterial gas embolism after breath-hold diving in shallow water. Pediatrics 136(3):e687-e690

51. Guidetti V, Dosi C, Bruni O (2014) The relationship between sleep and headache in children: implications for treatment. Cephalalgia 34(10):767-776

52. Bellini B, Panunzi S, Bruni O et al (2013) Headache and sleep in children. Curr Pain Headache Rep 17:335

53. Luc ME, Gupta A, Birnberg JM et al (2006) Characterization of symptoms of sleep disorders in children with headache. PediatrNeurol 34:7-12

54. Antoniazzi AL, Bigal ME, Bordini CA et al (2003) Headache and hemodialysis: a prospective study. Headache 43:99-102

55. Jain SR, Smith L, Brewer ED et al (2001) Non-invasive intravascular monitoring in the pediatric hemodialysis population. PediatrNephrol 16:15-18

56. Anyaegbu El, Dharnidharka VR (2014) Hypertension in the teenager. PediatrClin N Am 61:131-151
57. Croix B, Feig DI (2006) Childhood hypertension is not a silent disease. Pediatr Nephrol 21:527-532

58. Bijlsma MW, Blufpand HN, Kaspers GJ et al (2014) Why pediatricians fail to diagnose hypertension: a multicenter survey. J Pediatr 164:173-177

59. Sinha MD, Reid CJD (2007) Evaluation of blood pressure in children. Curr Opin Nephrol Hypertens 16:577-584

60. Norbedo S, Naviglio S, Murru FM et al (2014) A boy with sudden headache. Pediatr Emerg Care 30(3):182-184

61. Angus PD (2013) Don't forget phaeochromocytoma in the differential diagnosis of thunderclap headache. BMJ 346:682

62. Ludwig AD, Feig DI, Brandt ML et al (2007) Recent advances in the diagnosis and treatment of pheochromocytoma in children. Am J Surg 194:792-797

63. Gupta A, Agarwala S, Tandon N et al (2014) Pheochromocytoma management, outcomes and the role of cortical preservation. Indian J Pediatr 81:780-784

64. Abdullah I, Cossey K, Jeanmonod RK (2011) Extra-adrenal pheochromocytoma in an adolescent. West J Emerg Med 12:258-261

65. Yang WC, Zhao LL, Chen CY et al (2012) First-attack pediatric hypertensive crisis presenting to the pediatric emergency department. BMC Pediatr 12:200

66. Chandar J, Zilleruelo G (2012) Hypertensive crisis in children. Pediatr Nephrol 27:741-751

67. Milani GP, Edefonti A, Tardini G et al (2014) Severe and isolated headache associated with hypertension as unique clinical presentation of posterior reversible encephalopathy syndrome. BMC Pediatr 14:190

68. Yang WC, Wu HP (2010) Clinical analysis of hypertension in children admitted to the emergency department. Pediatr Neonatol 51:44-51

69. Leppälahti S, Gissler M, Mentula M, et al (2013) Is teenage pregnancy an obstetric risk in a welfare society? A population-based study in Finland, from 2006 to 2011. BMJ Open 3(8):e003225

70. Crovetto F, Somigliana E, Peguero A et al (2013) Stroke during pregnancy and pre-eclampsia. Curr Opin Obstet Gynecol 25:425-432

71. Furlan JC (2011) Headache attributed to autonomic dysreflexia. An unrecognized clinical entity. Neurology 23:792-798

72. Schottler J, Vogel LC, Sturm P (2012) Spinal cord injuries in young children: a review of children injured at 5 years of age and younger. Dev Med Child Neurol 54(12):1138-1143

73. Hickey KJ, Vogel LC, Willis KM et al (2004) Prevalence and etiology of autonomic dysreflexia in children with spinal cord injuries. J Spinal Cord Med 27:54-60

74. Ekici B, Cebeci AN (2015) The debate on the link between subclinical hypothyroidism and childhood migraine: is initial endocrinological evaluation necessary for children with migraine? Acta Neurol Belg 115(2):123-127

75. Fallah R, Mirouliaei M, Bashardoost N et al (2012) Frequency of subclinical hypothyroidism in 5- to 15-year-old children with migraine headache. J Pediatr Endocrinol Metab 25:859-862

76. Mosek A, Korczyn AD (1995) Yom Kippur headache. Neurology 45:1953-1955

77. Torelli P, Manzoni GC (2010) Fasting headache. Curr Pain Headache Rep 14:284-291

78. Torelli P, Evangelista A Bini A et al (2009) Fasting headache: a review of the literature and new hypotheses. Headache 49:744-752

79. Xu J, Gao Y, Li Y et al (2015) Left atrial myoxma presenting as headache in the pediatric patient. J Emerg Med 48(2):161-164

80. Watanabe T, Ono H, Morimoto Y, et al (2015) Skull involvement in a pediatric case of chronic recurrent multifocal osteomyelitis. Nagoya J Med Sci 77(3):493-500

81. PaivaBertoli FM, Antoniuk SA, Bruck I, et al (2007) Evaluation of the signs and symptoms of temporomandibular disorders in children with headaches. Arq Neuro-Psiquiatr 65:2

82. Motghare V, Kumar J, Kamate S, et al (2015) Association between harmful oral habits and sign and symptoms of temporomandibular joint disorders among adolescents. J Clin Diagn Res 9(8):45-48

83. Lei J, Liu MQ, Yap AU, et al (2015) Sleep disturbance and psychologic distress: prevalence and risk indicators for temporomandibular disorders in a Chinese population. See comment in PubMed Commons below. J Oral Facial Pain Headache 29(1):24-30

84. Müller L, Waes H, Langerweger C, et al (2013) Maximal mouth opening capacity: percentiles for healthy children 4-17 years of age. Pediatr Rheumatol Online J 11:17 
85. Branco LP, Santis TO, Alfaya TA, et al (2013) Association between headache and temporomandibular joint disorders in children and adolescents. J Oral Sci 55(1):39-43

86. Guidetti V, Galli F, Sheftell F (2011). "Headache attributed to psychiatric disorders". In: Nappi G, Moskowitz M (eds). Handbook in Clinical Neurology 97(55):657-662

87. Amouroux R, Rousseau-Salvador C (2008) Anxiety and depression in children and adolescents with migraine: a review of the literature. Encephale 34:504-510

88. Guidetti V, Galli F, Fabrizi P, et al (1998) Headache and psychiatric comorbidity: clinical aspects and outcome in 8-year follow-up study. Cephalalgia 19:211-219

89. Just U, Oelkers R, Bender S, et al (2003) Emotional and behavioural problems in children and adolescents with primary headache. Cephalalgia 23:206-213

90. Al-Twaijri WA, Shevell MI (2002) Pediatric migraine equivalents: occurrence and clinical features in practice, Pediatr Neurol 26:365-368

91. Grazzi L, Usai S, Rigamonti A (2005) Facial pain in children and adolescents. Neurol Sci 26:101-103

\section{Submit your manuscript to a SpringerOpen ${ }^{\circ}$ journal and benefit from:}

- Convenient online submission

- Rigorous peer review

- Open access: articles freely available online

- High visibility within the field

- Retaining the copyright to your article

Submit your next manuscript at $\gg$ springeropen.com 